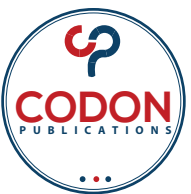

\title{
Stability evaluation of iron and vitamin A during processing and storage of fortified pasta
}

\author{
N. Sharma, S. Sharma, B. Singh, and G. Kaur \\ Department of Food Science and Technology, Punjab Agricultural University, Ludhiana, Punjab 141001, India
}

Corresponding Author: Neha Sharma; nehaatft12@gmail.com

Received: 29 November 2019 / Accepted: 24 December 2019 / Published: 03 June 2020 (C) 2020 Codon Publishers

OPEN ACCESS (c) (i) (2) (2) RESEARCH ARTICLE

\begin{abstract}
Pasta holds greater potential for improving the nutritional status of the population and its fortification with micronutrients like iron and vitamin A could be an effective strategy to provide the essential nutrients in the diet. This study quantified the losses of two different micronutrients (iron and vitamin A) in fortified pasta postprocessing and during storage for 4 months. Chemical salts of iron, namely, ferric sodium ethylene diamine tetra-acetic acid ( $\mathrm{NaFeEDTA})$ and ferrous sulphate $\left(\mathrm{FeSO}_{4}\right)$, were added to pasta formulation at 4,5,6 $\mathrm{mg} / 100 \mathrm{~g}$ and 6,7,8 $\mathrm{mg} / 100 \mathrm{~g}$ respectively, whereas for vitamin A, retinyl acetate (RA) was added at 700, $800 \mathrm{md} 900 \mathrm{\mu g} / 100 \mathrm{~g}$. After processing, the prepared pasta with both iron salts showed retention of $94-95 \%$ for iron and $90-92 \%$ of vitamin A activity. Iron and vitamin A-fortified pasta with maximum retention during processing and exhibiting optimum colour attributes and sensory score were stored alone and in combination (NaFeEDTA and RA) at 25 and $40{ }^{\circ} \mathrm{C}$ in laminates (aluminium laminates) and polypropylene packets for a period of 4 months and evaluated for changes in their iron and vitamin A contents. An overall retention of 93-95\% of the iron and 56-62\% of vitamin A was observed after 4 months considering losses during processing and storage. Variations in temperature had a non-significant effect on the stability of iron, whereas for vitamin A a loss of 33-37\% was noted for pasta stored at accelerated temperature of $40{ }^{\circ} \mathrm{C}$. Among the two packaging materials used, laminates retained more of iron and vitamin A activity than polypropylene. No difference in retention rates was observed for iron and vitamin A when fortified alone or in combination.
\end{abstract}

Keywords: pasta; micronutrients; vitamins; storage

\section{Introduction}

'Micronutrients' is the term applied to all essential vitamins and minerals that are required by the body in very minute quantities throughout life to perform a range of physiological functions. According to the reports of Food Agriculture Organization (FAO, 2013), more than 2 billion people are suffering from one or the other micronutrient affliction. The deficiencies were mostly found for vitamin A, folate, iron, iodine and zinc. Pregnant women and children aged 5 years or less are the most susceptible population subgroups.Globally, the World Health Organization (WHO) estimates that $25 \%$ of the population (1.62 billion people) is suffering from anaemia and among them the highest prevalence was observed in preschool children (47.4\%) and pregnant women (41.8\%). Because of the deficiency of vitamin A, night blindness affects 5.2 million preschool age children and 9.8 million pregnant women, which corresponds to 0.9 and $7.8 \%$ of the population, respectively (WHO, 2009). 
Recently, a number of food-based strategies or approaches have been adopted and applied to address the problem of micronutrient deficiency like dietary diversification and direct supplementation. However, numerous factors govern their implementation, for instance acquiescent behaviour, consistent financial support from the government or international donors and national health care distribution systems that may or may not be equally accessible to various segments of the population. Fortification of food is a cost-effective, flexible and generally acceptable method to improvise the nutrient intake of groups at risk in order to guarantee nutritional adequacy of the diet (Hoffpauer and Wright, 1994). In any fortification programme, choice of a suitable fortificant is one of the major considerations that determine the success or failure of that programme. The fortification vehicle can be either a staple food or a more processed, commercially available product that is affordable, palatable and ethically acceptable. However, it is of prime importance to assess the physiochemical changes taking place in the vehicle carrying the fortificant, as it should retain its original characteristics after fortification and under local conditions of storage (Flour Fortification Initiative [FFI], 2008).

In most of the developing countries, $95 \%$ of the population consumes cereals or cereal-based products, which makes them an appropriate vehicle for the fortification programme (Ranum, 2000). However, the biggest problem associated with the fortification of cereal based food with iron is the presence of phytate, which chelates with the iron present in cereal based foods and renders it unsuitable for absorption under physiological conditions (Fiel, 2001), and sometimes oxidative status of iron also decides its absorption rate. The chemical nature of vitamin A (the presence of double bonds, esters, aldehydes or alcohols) determines their stability in the fortified foods. The need for fortification of commonly consumed foods was realised long before and has already been implemented in many countries globally. A number of attempts have been made to fortify various types of cereal-based foods with iron and vitamin A, for example, sugar (Bauernfeind, 1991; Molina, 1991), salt (Nestel, 1993), Mono Sodium Glutamate (MSG) (Bauernfeind, 1991; Nestel, 1993), oils (Combs et al., 1994; Nestel, 1993), margarine (Bauerfiend, 1991), rice (Lee et al., 2000), and bread and maize flour (Alam et al., 2007; Cort et al., 1976; Crandall et al., 2014; Tripathi et al., 2012). The efficacy results and implementation at a large scale had a positive impact on the improvement of the micronutrient status of people. However, calorie intake, loss of nutrients during processing and health-related issues associated with some of these foods are certain factors that limit their use as fortification vehicles. In spite of an increased recognition of the importance of fortification, pasta epitomised the unexploited potential for contributing good nutrition through fortification. Pasta, an economical food typically prepared from durum wheat, is consumed worldwide by people of all age groups. Technically, pasta can be an excellent vehicle for the production of novel fortified products because it is a cold-extruded product, and additives can be easily blended into its formula with little changes to the micronutrient content. For pasta and noodles, fortification can be done either by the use of fortified semolina or by the wet dispersion of required vitamins or minerals, which can be carried out at the dough-making stage. In addition, economics of the product, ease of preparation, high storage stability and greater variability in its serving makes pasta an effective food fortification vehicle. The WHO and the Food Drug Administration (FDA) regard pasta as a suitable vehicle for the incorporation of nutrients (Chillo et al., 2008).

Therefore, the present investigation was planned to assess the potential and the stability of $\mathrm{NaFeEDTA}$ and $\mathrm{FeSO}_{4}$ as iron fortificants and retinyl acetate (RA) as a possible vitamin $\mathrm{A}$ fortificant during processing and under various conditions (temperature and packaging material) of storage for a period of 4 months.

\section{Materials and methods}

\section{Raw materials}

Commercial durum wheat semolina (Triticum durum L.) was purchased from the local market, Ludhiana, which was then stored in polyethylene terephthalate (PET) jars at room temperature, prior to further investigation. The fortificants, that is, ferric sodium ethylene di-amine-tetra acetic acid (NaFeEDTA) and ferrous sulphate $\left(\mathrm{FeSO}_{4} 7 \mathrm{H}_{2} \mathrm{O}\right)$ of food grade for iron, and $\mathrm{RA}$ of food grade for vitamin A were purchased from Central Drug House, Laboratory (P) Ltd.

\section{Proximate analysis}

For assessing the physicochemical composition of raw materials, standard methods (AACC, 2000) were used to estimate ash content (method 08-01) and protein $(N \times 5.75)$ for wheat semolina, and fat content was determined using a 16 -h soxhlet extraction with petroleum ether (AACC, 2000). Crude fibre of raw materials was estimated using Fibertec (FOSS). Per cent total carbohydrates were determined as $(100 \%$ estimated proximate components)

\section{Fortification of semolina blends}

Data in Table 2 show the fortificants used in the present investigation, with their respective micronutrient contents, their targeted levels and their amounts to be 
added in pasta. The fortificants were mixed thoroughly with semolina by sieving them thrice through a 20 bss mesh sieve.

\section{Pasta preparation}

For the preparation of micronutrient-fortified pasta, fortificant-semolina blends were mixed with an optimum amount of water in the mixing compartment of a pasta extruder (le monferrina Masoero Arturo and C.S.N.C., Italy) for $10 \mathrm{~min}$ to obtain a uniformly mixed semolina dough (30-32\% moisture) at constant extrusion temperature of not more than $50{ }^{\circ} \mathrm{C}$. The moist semolina mixture was passed to a metal extruder attachment of the pasta machine fixed with an adjustable die (fusilli shaped). Extruded pasta was dried at $45-50{ }^{\circ} \mathrm{C}$ in a hot air oven for about $4-5 \mathrm{~h}$ to attain the final moisture of $6.5 \%$. The resultant dried products of various fortificant blends were packed in high-density polyethylene (HDPE) bags for subsequent analysis (Kaur et al., 2015).

Table 1. Proximate composition of raw semolina.

\begin{tabular}{ll}
\hline Components & \\
\hline Moisture (\%) & $14.00 \pm 0.40$ \\
Ash (\%) & $1.51 \pm 0.31$ \\
Protein (\%) & $11.33 \pm 1.2$ \\
Fat (\%) & $2.01 \pm 0.18$ \\
Fibre (\%) & $1.13 \pm 0.22$ \\
Carbohydrates (\%) & $70.02 \pm 2.3$ \\
Iron (mg/100 g) & $1.99 \pm 0.08$ \\
Vitamin A (RE $\mu \mathrm{g} / 100 \mathrm{~g})$ & $22.85 \pm 3.2$ \\
\hline$n($ no. of samples) $=3$. &
\end{tabular}

\section{Micronutrient analysis}

\section{Iron estimation}

Iron contents of fortificant semolina blends and the prepared pasta were estimated by the wet ashing method using a Flame Atomic Absorption Spectrophotometer (Varion AAS-FS 240 model, US). Accurately weighed 1 $\mathrm{g}$ of the sample was digested in $20 \mathrm{ml}$ of concentrated $\mathrm{HNO}_{3}$ and $\mathrm{HCl}(1: 1, \mathrm{v} / \mathrm{v})$ solution until one-fourth fraction of the mixture remained. The digested sample was kept for cooling to room temperature and diluted to $100 \mathrm{ml}$ using distilled water. The Fe cathode lamp (248.3 $\mathrm{nm}$ wavelength) was used for applying the AAS-flame. From an iron stock solution $(1,000 \mathrm{mg} / \mathrm{L})$, a series of $\mathrm{Fe}$ standard solutions $(0-5 \mathrm{mg} / \mathrm{L})$ were prepared to obtain the standard curve for iron (AOAC, 2005).

\section{Vitamin A estimation}

An amount of $1 \mathrm{~g}$ of finely ground sample (40 bss mesh sieve) was taken in a 50-ml centrifuge tube and $5 \mathrm{ml}$ of methanol-ascorbic acid $(0.1 \%)$ and $4 \mathrm{ml}$ of $\mathrm{KOH}$ solution (12.5\%) were added into it. The content was first heated in a water bath at $70^{\circ} \mathrm{C}$ for $30 \mathrm{~min}$, vortexed for proper mixing and then cooled to room temperature. Extraction of vitamin A was carried out with $5 \mathrm{ml} \mathrm{n}$-hexane. The hexane fraction was collected. The extraction process was continued with $1 \mathrm{ml}$ of methanol-ascorbic acid solution (0.1\%) and $20 \mathrm{ml}$ of $\mathrm{n}$-hexane. Hexane fraction was collected again and added back to the fraction obtained above and evaporated to dryness. High Performance Liquid Chromatography (HPLC) grade methanol was added in the dried hexane collection for re-dilution, transferred to a $50 \mathrm{ml}$ volumetric flask and brought to volume using the same and filtered through a $0.45 \mu \mathrm{m}$ filter. Samples and standard solution $(20 \mu \mathrm{l})$ were injected

Table 2. Micronutrient fortificants and their fortification levels.

\begin{tabular}{|c|c|c|c|c|}
\hline Micronutrient & Fortificant & $\begin{array}{l}\text { Micronutrient content in } \\
\text { the fortificant source }\end{array}$ & $\begin{array}{l}\text { Targeted level of micronutrient } \\
\text { to be added in product }\end{array}$ & $\begin{array}{c}\text { Amount of fortificant } \\
\text { source added }\end{array}$ \\
\hline & & & 4 & 307 \\
\hline \multirow[t]{6}{*}{ Iron } & NaFeEDTA & $13 \%$ & 5 & 384 \\
\hline & $(\mathrm{mg} / 100 \mathrm{~g})$ & & 6 & 462 \\
\hline & & & 6 & 182 \\
\hline & $\mathrm{FeSO}_{4}$ & $33 \%$ & 7 & 212 \\
\hline & $(\mathrm{mg} / 100 \mathrm{~g})$ & & 8 & 242 \\
\hline & & & 700 & 4240 \\
\hline \multirow[t]{2}{*}{ Vitamin A } & Retinyl Acetate & $500000 \mathrm{IU} / \mathrm{g}$ & 800 & 4804 \\
\hline & $(\mu \mathrm{g} / 100 \mathrm{~g})$ & & 900 & 5405 \\
\hline
\end{tabular}


separately and analysed with HPLC (Waters e2695, USA) having a UV-VIS detector with RP-18 column. Methanol was used as a mobile phase with a flow rate of $0.7 \mathrm{ml} / \mathrm{min}$. Vitamin A was measured at a wavelength of $323 \mathrm{~nm}$. A standard solution of RA with a working standard concentration of $5 \mu \mathrm{g} / \mathrm{ml}$ was used in every run to assure accurate quantification. Until analysis, all ground samples were stored under dark at $4{ }^{\circ} \mathrm{C}$ (Ministry of Health of the People's Republic of China, 2010).

\section{Colour analysis}

The colour of the prepared pasta was determined in triplicates using a colorimeter (Minolta CR 300, Japan). Measurements were taken at random positions on the surface of the pasta, and colour parameters like $L^{*}, a^{*}$ and $b^{*}$ values were noted. Three measurements were recorded for each sample and are represented as averages.

\section{Overall acceptability}

Sensory analysis of cooked pasta was carried out using the nine-point hedonic scale (Ranganna, 1986) by a semitrained panel of 15 members. The panel evaluated the pasta for sensory parameters like colour, appearance, texture and taste, and the mean value of the score was considered as overall acceptability.

\section{Storage of micronutrient-fortified pasta}

Pasta with selected or optimised levels of fortificants (alone and in combination) was prepared as described in Table 5 and stored in two different packaging materials, that is, aluminium laminates (150 gauge; WVTR:
$3,000 \mathrm{~cm}^{3 /} \mathrm{m}^{2} / 24 \mathrm{~h}$ ) and polypropylene (150 gauge; WVTR: $2,000 \mathrm{~cm}^{3 /} \mathrm{m}^{2} / 24 \mathrm{~h}$ ) at 25 and $40{ }^{\circ} \mathrm{C}$, respectively, for a period of 4 months under natural light. The stored pasta samples were withdrawn at the end of every month and analysed for micronutrient content and retention.

$$
\begin{aligned}
& \text { micronutrient conc } \\
& \text { (initial month)- } \\
& \text { micronutrient conc } \\
& \text { Retention }(\%)=100-\frac{(\text { final month })}{\text { micronutrient conc }} \\
& \text { (initial month) }
\end{aligned}
$$

\section{Statistical analysis}

For comparison of iron and vitamin A content of fortified semolina blends and fortified pasta, paired samples $t$-test was used. Data obtained during storage were analysed with analysis of variance (ANOVA). Post hoc (Tukey's b) multiple comparison test was applied to obtain significant differences in the mean content of micronutrients in fortified pasta stored for a period of 4 months.

\section{Results and discussion}

\section{Effect of processing on the micronutrient content of fortified pasta}

\begin{tabular}{|c|c|c|c|c|}
\hline Fortificant & Fortification level & Semolina blends & Pasta & Retention (\%) \\
\hline \multicolumn{5}{|l|}{ Iron (mg/100g) } \\
\hline Control & - & $1.99 \pm 0.14$ & $1.84 \pm 0.38$ & $92.46 \pm 0.55$ \\
\hline \multirow[t]{3}{*}{ NaFeEDTA } & 4 & $5.56 \pm 0.28$ & $5.29 \pm 0.06$ & $95.20 \pm 0.04$ \\
\hline & 5 & $6.37 \pm 0.25$ & $6.07 \pm 0.06$ & $95.25 \pm 0.04$ \\
\hline & 6 & $7.60 \pm 0.16$ & $7.25 \pm 0.04$ & $95.35 \pm 0.03$ \\
\hline \multirow[t]{3}{*}{$\mathrm{FeSO}_{4}$} & 6 & $7.59 \pm 0.31$ & $7.14 \pm 0.10$ & $94.07 \pm 0.50$ \\
\hline & 7 & $8.39 \pm 0.20$ & $7.91 \pm 0.23$ & $94.03 \pm 0.30$ \\
\hline & 8 & $9.63 \pm 0.19$ & $9.09 \pm 0.14$ & $94.44 \pm 0.40$ \\
\hline \multicolumn{5}{|c|}{ Vitamin A ( $\mu \mathrm{g}$ RE/100g) } \\
\hline Control & - & $22.85 \pm 0.04$ & $21.64 \pm 0.04$ & $94.70 \pm 0.08$ \\
\hline \multirow[t]{3}{*}{ Retinyl acetate } & 700 & $660.50 \pm 10.60$ & $594.18 \pm 8.48$ & $90.03 \pm 1.03$ \\
\hline & 800 & $742.00 \pm 8.48$ & $682.64 \pm 10.60$ & $91.89 \pm 2.85$ \\
\hline & 900 & $816.48 \pm 14.14$ & $755.60 \pm 16.97$ & $92.55 \pm 2.00$ \\
\hline
\end{tabular}

Iron

The data of the mean iron content of both fortificant semolina blends and resultant pasta are represented in

Table 3. Stability of iron and vitamin A in fortified pasta during processing. 
Table 4. Colour of iron- and vitamin-A-fortified pasta.

\begin{tabular}{|c|c|c|c|c|c|}
\hline Micronutrient & Fortificant & Fortification level & $L^{*}$ & $a^{*}$ & $\mathbf{b}^{*}$ \\
\hline Control & - & - & $55.154 \pm 0.322$ & $0.420 \pm 0.028$ & $8.56 \pm 0.128$ \\
\hline \multirow[t]{6}{*}{ Iron } & $\mathrm{NaFeEDTA}(\mathrm{mg} / 100 \mathrm{~g})$ & 4 & $56.163 \pm 0.265$ & $0.416 \pm 0.025$ & $8.37 \pm 0.045$ \\
\hline & & 5 & $55.553 \pm 0.526$ & $0.470 \pm 0.017$ & $8.54 \pm 0.158$ \\
\hline & & 6 & $55.530 \pm 1.140$ & $0.473 \pm 0.040$ & $8.54 \pm 0.155$ \\
\hline & $\mathrm{FeSO}_{4}(\mathrm{mg} / 100 \mathrm{~g})$ & 6 & $52.720 \pm 0.295$ & $0.510 \pm 0.017$ & $9.51 \pm 0.028$ \\
\hline & & 7 & $51.803 \pm 1.143$ & $0.524 \pm 0.034$ & $9.69 \pm 0.105$ \\
\hline & & 8 & $50.850 \pm 0.112$ & $0.540 \pm 0.032$ & $9.84 \pm 0.189$ \\
\hline \multirow[t]{3}{*}{ Vitamin A } & Retinyl Acetate $(\mu \mathrm{g} / 100 \mathrm{~g})$ & 700 & $55.70 \pm 0.597$ & $0.50 \pm 0.020$ & $8.63 \pm 0.24$ \\
\hline & & 800 & $53.87 \pm 1.570$ & $0.65 \pm 0.110$ & $8.68 \pm 0.21$ \\
\hline & & 900 & $54.10 \pm 2.180$ & $0.57 \pm 0.03$ & $8.74 \pm 0.04$ \\
\hline
\end{tabular}

Table 3. Control (semolina) contained $1.99 \mathrm{mg} / 100 \mathrm{~g}$ of total iron content. Addition of iron fortificants into the semolina at varying levels significantly $(P \leq 0.05)$ raised their iron contents. With an increase in the level of NaFeEDTA added into the semolina, from 4 to $6 \mathrm{mg} / 100 \mathrm{~g}$, the total iron concentration increased from $1.99 \mathrm{mg} / 100 \mathrm{~g}$ in control to $5.56-7.60 \mathrm{mg} / 100$ g. Similarly, for $\mathrm{FeSO}_{4}$ incorporation into the semolina, the same trend was observed, with an increase in iron content from $1.99 \mathrm{mg} / 100 \mathrm{~g}$ (control) to 7.59, 8.39 and $9.63 \mathrm{mg} / 100 \mathrm{~g}$, with their respective levels of fortificant addition as discussed earlier. The increased iron contents are correlated with the addition of fortificants at varying levels. Our results are in close agreement with the study conducted by Ayelign et al. (2011), where they reported that wheat flour fortified with ferrous sulphate at a level of $40 \mathrm{ppm}$ contributed to an increase to $55.51 \mathrm{ppm}$ in the total iron content in fortified flour. Different fortificants behaved differently with respect to their micronutrient content, under different conditions of processing, which was also observed for the data for different iron fortificants in the present investigation. Iron is a mineral and is very stable when exposed to light, heat, temperature and extreme $\mathrm{pH}$ or other factors affecting the organic compounds (Miller, 2008). However, on processing of iron fortificant-semolina blends to pasta, both iron fortificants showed different retention rates. Control semolina when processed to pasta retained up to $92.46 \%$ of the total iron content $(1.99 \mathrm{mg} / 100 \mathrm{~g})$ when compared to the initial content (1.84 mg/100 g). However, higher iron retention rates were noticed in NaFeEDTA-fortified pasta than that fortified with $\mathrm{FeSO}_{4}$, with values ranging from 5.29 to $7.25 \mathrm{mg} / 100 \mathrm{~g}$ and corresponding retention rates of more than $95 \%$ at all three levels of NaFeEDTA addition. On the other hand, significant differences were observed between the iron contents of $\mathrm{FeSO}_{4}$-fortified semolina blends and their resultant pasta, as analysed by the paired samples $t$-test. More than $94 \%$ of retention was observed at all levels of $\mathrm{FeSO}_{4}$ addition. The superior rates of iron retention in case of NaFeEDTA-fortified pasta could be attributed to its highly stable structure, which resists leaching of iron from the EDTA structure. In a similar study by Le et al. (2007), it was observed that in the production of instant noodles, which includes deep-frying in oil at high temperatures $\left(140-160{ }^{\circ} \mathrm{C}\right.$ ), the iron content (added in the form of NaFeEDTA) was not affected.

\section{Vitamin A}

Data in Table 3 clearly depict the vitamin A content of the RA-fortified semolina blends and the prepared pasta. The mean vitamin A content in the control pasta was $22.85 \mu \mathrm{g} / 100 \mathrm{~g}$, which increased significantly $(P \leq 0.05)$ from 660.5 to $816.48 \mu \mathrm{g} \mathrm{RE} / 100 \mathrm{~g}$, as the level of addition of RA increased from 700 to $900 \mu \mathrm{g} / 100 \mathrm{~g}$. Processing of RA-fortified semolina blend to pasta significantly affected the vitamin A content of the product. The resultant pasta retained up to $90.03-92.55 \%$ of the total vitamin A. It was also observed that increasing the addition level of RA into the sample resulted in the reduction of vitamin A losses. Reported 90-100\% retention of vitamin A during baking. Butt et al. (2007) reported that vitamin A has excellent stability in cookies during baking, with losses falling in the range of $8.69-11.11 \%$. Similarly, a study conducted by Herawati et al. (2015) recorded more than 100\% retention of vitamin A, after baking the sweet potato flour cookies fortified with retinyl palmitate at $691.1 \mathrm{mg} / \mathrm{kg}$, which was attributed to the increased recovery during baking. In another similar study by Fratianni et al. (2012), it was reported that processing of pasta resulted in a steady increase in cis-retinol along with a slight decrease in trans-retinol because of the increase in the degree of isomerisation from cis- to trans-retinol, from $12 \%$ in mix to $32 \%$ in final pasta. 


\section{Colour analysis of micronutrient-fortified pasta}

Colour is the main concern in fortified food, especially iron-fortified foods, because colour changes frequently in these products, which in turn induces organoleptic changes in the food vehicle. Pasta samples had a particular colour profile. It had more yellow-white colour with high brightness. As depicted by the data presented in Table 4, L* values of NaFeEDTA- and RA- fortified pasta were almost similar to the control, whereas ferroussulphate-fortified pasta was observed to have reduced $L^{*}$ values. Iron in NaFeEDTA is protected within the EDTA structure; therefore, the use of NaFeEDTA as a fortificant might reduce the undesirable changes in colour of the fortified food. No significant $(P \leq 0.05)$ pattern appeared in the $\mathrm{a}^{*}$ values of pasta fortified with various fortificants used in the study except for ferrous sulphate, which was observed to be comparatively darker. The $b^{*}$ colour values followed the similar trend as that of $L^{*}$ values, with no significant changes in the NaFeEDTA- and RA-fortified pasta, whereas when $\mathrm{FeSO}_{4}$ was employed as a fortificant into the pasta, the degree of yellowness increased slightly when compared with control. These results might be due to the characteristics of ferrous sulphate, which causes colour alterations in foods more readily owing to its higher solubility in water. Our results are in agreement with the study conducted by Theuer (2002) who observed that addition of ferrous sulphate to wheat porridge resulted in significant changes in all the colour parameters of the porridge. Similarly, Kongachuichai (2007) also reported higher red and yellow tones for noodles fortified with ferrous sulphate at $5 \mathrm{mg}$ per serving. However, as reported by Reungmaneepaitoon and Sikkhamondhol (2008), no significant $(P \leq 0.05)$ changes in the $b^{*}$ values of rice pasta fortified with ferrous sulphate was noted with doubling the fortification level from $30 \%$ of Recommended Reference Intake (RDI) for iron to $60 \%$ into the pasta. The various levels of fortificants contributed significantly to the variation in the colour parameters, but it has no practical consideration as all values fall in such a narrow range. The instrumental colour effects of NaFeEDTA obtained in the present study contrasts with the results found in iron-fortified tortillas by Richins et al. (2008), who reported that addition of NaFeEDTA at a level of $16.98 \mathrm{mg} / 100 \mathrm{~g}$ reduced the $\mathrm{L}^{*}$ and a* values of unfortified tortilla from 71.25 and 0.42 to 66.16 and 0.28 , respectively.

\section{Sensory analysis of micronutrient-fortified pasta}

For any fortificant to be successfully added in a suitable food vehicle, it should not influence any of the sensory properties of the fortified food. According to Figure 1A, the general appearance scores for NaFeEDTA-fortified pasta samples at various levels were found not to be significantly different from the controlled one $(P \leq 0.05)$. No prominent differences were observed for the flavour profiles of the fortified samples and were similar to the controlled one. However, scores for the mouthfeel of the fortified ones are less. The overall acceptability scores of the fortified samples were almost similar to the controlled sample, with an average score ranging from 8.19 to 8.34. On the other hand, the panellists scored less for $\mathrm{FeSO}_{4}$-fortified pasta samples (Figure 1B), basically because of the dull appearance of the fortified sample, which is in contrast to the study conducted by Kongkachuichai et al. (2007) who reported no change in the sensory acceptability of instant noodles when fortified with $\mathrm{NaFeEDTA}$ and $\mathrm{FeSO}_{4}$, at various levels.

RA-fortified pasta samples (Figure 1C) again exhibited no significant differences between the fortified and controlled samples with regard to their appearance, mouthfeel and the overall acceptability, with average scores ranging from 8.31 to 8.40 .
A

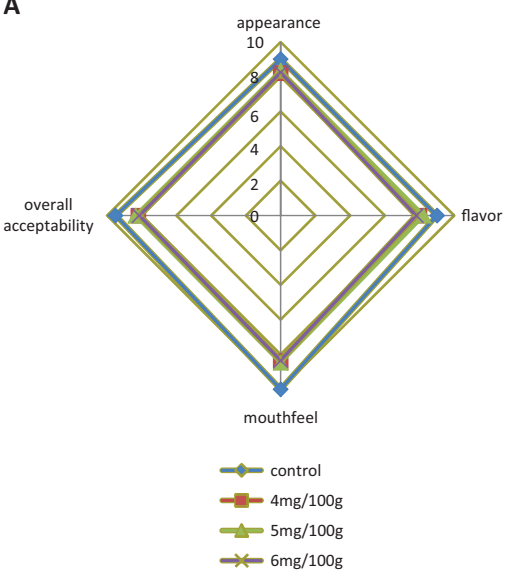

B

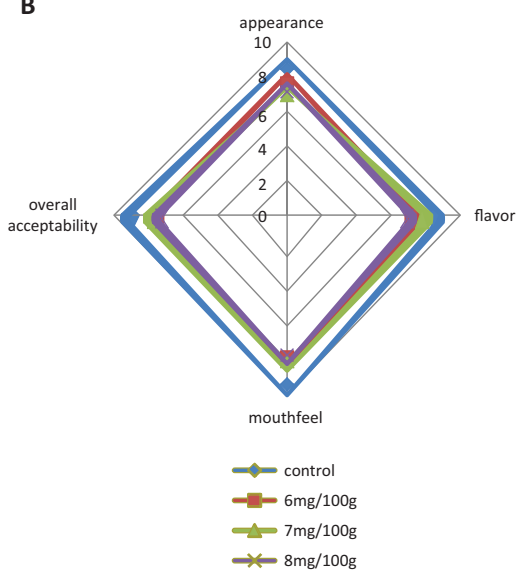

C

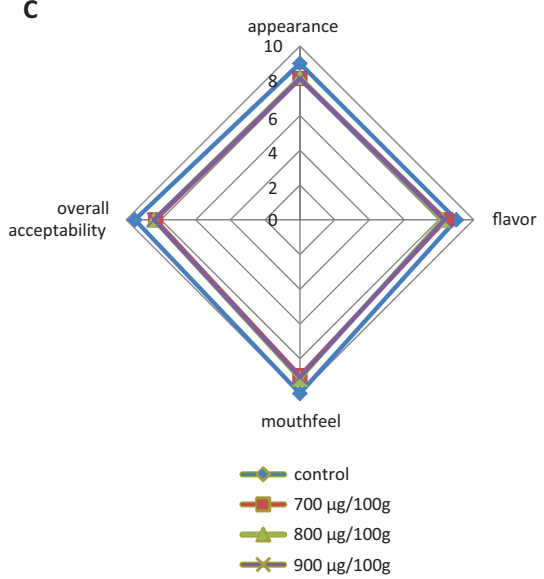

Figure 1. Organoleptic quality of (A) NaFeEDTA fortified pasta, (B) FeSO4 fortified pasta and (C) Retinyl Acetate fortified pasta. 
the second month, which further decreased significantly to $5.71 \mathrm{mg} / 100 \mathrm{~g}$ at the end of fourth month of storage, corresponding to an overall retention of $94.16 \%$ as observed with samples stored in polypropylene packets at $40{ }^{\circ} \mathrm{C}$. Similarly, for ferrous-sulphate-fortified pasta, the overall retention was $94.17 \%$-the initial mean iron concentration of $7.91 \mathrm{mg} / 100 \mathrm{~g}$ was reduced to $7.44 \mathrm{mg} / 100 \mathrm{~g}$ after 4 months of storage. The loss of iron during storage could be attributed to the interaction of electron-deficient iron, especially in ferrous sulphate, with other components of food, such as protein and carbohydrates, which form stable complexes with electron-rich food components (Clydesdale, 1999). Rosado et al. (2005) reported that iron content of tortillas prepared from flour fortified with iron for a period of 60 days decreased significantly from 4.2 to $3.6 \mathrm{mg} / 100 \mathrm{~g}$, suggesting an overall loss of $14 \%$ iron. In a similar study conducted by Kuong et al. (2016) for the storage of iron-fortified cold extruded rice, it was reported that more than $90 \%$ of the iron was retained after 12 months of storage. Storage temperature and packaging materials did not affect the iron concentration of the fortified pasta in the present investigation. However, insignificant variations were observed in the mean iron content of $\mathrm{NaFeEDTA}$-fortified pasta stored at 25 and $40{ }^{\circ} \mathrm{C}$, with a slight alteration in the contents from $5.75 \mathrm{mg} / 10 \mathrm{~g}$ to $5.73 \mathrm{mg} / 100 \mathrm{~g}$, respectively. Kuong et al. (2016) studied the storage stability of iron in cold-extruded rice stored at 20 and $40^{\circ} \mathrm{C}$, and they reported that the product stored at $20{ }^{\circ} \mathrm{C}$ showed higher retention (100.5\%) when compared to the product stored at $40{ }^{\circ} \mathrm{C}(99.70 \%)$ for 6 months. However, studies by Ayelign et al. (2012) reported that higher temperature of storage and relative humidity did not affect the iron content of fortified flour during storage for 4 days. Li et al. (2008) also reported no loss of iron in the NaFeEDTA-fortified ultra-rice after 32 weeks of storage. Studies of FFI (2015) for the assessment of iron retention in instant noodles prepared from wheat flour fortified with different iron fortificants (electrolytic iron, ferrous fumarate, encapsulated ferrous fumarate and NaFeEDTA) indicated insignificant losses of iron when stored for a period of 42 weeks at $25,30,35$ and $40^{\circ} \mathrm{C}$, respectively. At $35^{\circ} \mathrm{C}$, less than $10 \%$ losses were recorded in instant noodles when iron was added in the form of ferrous fumarate after storage of 26 weeks. When fortified with electrolytic, encapsulated ferrous fumarate or NaFeEDTA or at different storage conditions (e.g. at $40^{\circ} \mathrm{C}$ for 18 weeks). As iron is a mineral and is stable on exposure to light, insignificant changes in the overall iron concentration was observed for both fortificants packed in laminates and polypropylene.

\section{Effect of storage on the vitamin A content of RA-fortified pasta}

Data for the stability of RA or vitamin A in fortified pasta during 4 months of storage at different conditions are represented in Table 6. On the whole, RA stability appeared to be more affected by storage period than temperature of storage and the packaging materials used. RA-fortified pasta when stored initially contained $673.12 \mu \mathrm{g}$ RE per $100 \mathrm{~g}$ of pasta, which after storage of 4 months decreased to $450.69 \mu \mathrm{g} R \mathrm{RE}$ per $100 \mathrm{~g}$ of pasta. About one-third of the total vitamin A was found to be lost on storage for 4 months. The losses in vitamin $\mathrm{A}$ in the stored vitamin-A-fortified pasta sample are attributed mainly to the photo-isomerisation in the presence of light, and oxidative degradation by free radical attack during storage. In a similar work, Butt et al. (2007) studied the retention of RA in vitamin-A-fortified cookies during storage of 30 days at ambient temperature and observed more than $89 \%$ of retention. In another study, Kuong et al. (2016) stated that more than $70 \%$ of vitamin A was retained after storage of 6 months at ambient temperature. Temperature of storage was found to be indirectly proportional to the stability of RA. The loss of vitamin A activity in the case of laminated products stored at $25^{\circ} \mathrm{C}$ was $30.47 \%$ when assessed after 4 months, whereas its other counterpart (polypropylene packaged) lost up to $33.85 \%$ when kept at $40^{\circ} \mathrm{C}$. The increased losses of vitamin $\mathrm{A}$ at higher temperatures could be due to the heat-induced kitol formation, which follows second-order rate law (Runge and Heger, 2000). Lee et al. (2000) in their study reported that at $23{ }^{\circ} \mathrm{C}$, the overall vitamin A retention was $86.6 \%$, while storage of fortified rice at a higher temperature of $40^{\circ} \mathrm{C}$ for a period of 6 months resulted in a loss of $49 \%$ of vitamin A. In another study by Kuong et al. (2016), more than 65\% loss of vitamin A was observed for vitamin-A-fortified, cold-extruded rice after storage of 6 months at $40{ }^{\circ} \mathrm{C}$ and $75 \%$ of relative humidity, whereas the same samples when stored at $25{ }^{\circ} \mathrm{C}$ retained up to $84 \%$ of vitamin $\mathrm{A}$.

Packaging is expected to exclude all those environmental factors that can reduce nutrient retention in the system. A detailed description of the effect of various packaging materials and conditions on the stability of various vitamins in cereal grain products is reviewed by Ott (1988). The various types of packaging materials discussed in the study had a profound effect on the RA content of pasta. RA, a vitamin A fortificant, is highly susceptible to deterioration when exposed to light for a longer duration of time. The mean vitamin A content of laminate-packaged pasta was $456.61 \mu \mathrm{g}$ RE per $100 \mathrm{~g}$, whereas polypropylene-packaged pasta retained $444.76 \mu \mathrm{g} \mathrm{RE} / 100 \mathrm{~g}$ of pasta at the end of the last month of storage. Under the experimented storage conditions and at each moment, retention of RA was always significantly higher in laminate-packaged pasta stored at $25{ }^{\circ} \mathrm{C}$. Our results are in line with those of Pinkaew et al. (2012) who reported that storage of retinyl-palmitate-fortified, hot-extruded artificial rice in aluminium-foiled packets for a period of 18 weeks showed $18 \%$ higher retention of retinyl palmitate than those stored in polyethylene transparent packets with $40 \%$ degradation. 
Table 7. Stability of iron and vitamin A in double micronutrient fortified pasta during storage.

\begin{tabular}{|c|c|c|c|c|c|c|c|}
\hline \multirow[t]{2}{*}{ Packaging Material } & \multirow[t]{2}{*}{ Temp. $\left({ }^{\circ} \mathrm{C}\right)$} & \multicolumn{5}{|c|}{ Storage period (months) } & \multirow[t]{2}{*}{ Retention (\%) } \\
\hline & & 0 & 1 & 2 & 3 & 4 & \\
\hline \multicolumn{8}{|l|}{ Iron (mg/100g) } \\
\hline \multirow[t]{2}{*}{ Laminates } & 25 & $6.07 \pm 0.04^{\mathrm{aA}}$ & $6.03 \pm 0.04^{\mathrm{abA}}$ & $5.94 \pm 0.06^{\mathrm{bcA}}$ & $5.86 \pm 0.08^{\mathrm{cA}}$ & $5.79 \pm 0.06^{\mathrm{cA}}$ & 95.42 \\
\hline & 40 & $6.07 \pm 0.04^{\mathrm{Aa}}$ & $6.01 \pm 0.02^{\mathrm{abA}}$ & $5.91 \pm 0.02^{\mathrm{bcA}}$ & $5.84 \pm 0.08^{\mathrm{cdA}}$ & $5.78 \pm 0.07^{\mathrm{dA}}$ & 95.27 \\
\hline \multirow[t]{2}{*}{ Polypropylene } & 25 & $6.07 \pm 0.04^{\mathrm{Aa}}$ & $6.02 \pm 0.02^{\mathrm{abA}}$ & $5.94 \pm 0.04^{\mathrm{bcA}}$ & $5.84 \pm 0.08^{\mathrm{cdA}}$ & $5.78 \pm 0.04^{\mathrm{dA}}$ & 95.27 \\
\hline & 40 & $6.07 \pm 0.04^{\mathrm{Aa}}$ & $6.01 \pm 0.08^{\mathrm{abA}}$ & $5.93 \pm 0.06^{\mathrm{bcA}}$ & $5.81 \pm 0.04^{\mathrm{cdA}}$ & $5.73 \pm 0.03^{\mathrm{dA}}$ & 94.55 \\
\hline \multicolumn{8}{|c|}{ Vitamin $A(\mu \mathrm{g} E / 100 \mathrm{~g})$} \\
\hline \multirow[t]{2}{*}{ Laminates } & 25 & $673.12 \pm 2.80^{\mathrm{Aa}}$ & $621.18 \pm 3.60^{\mathrm{bA}}$ & $569.11 \pm 2.60^{\mathrm{cA}}$ & $502.38 \pm 7.22^{\mathrm{dA}}$ & $465.01 \pm 2.42^{\mathrm{eA}}$ & 69.08 \\
\hline & 40 & $673.12 \pm 2.80^{\mathrm{Aa}}$ & $608.00 \pm 4.20^{\mathrm{Bb}}$ & $542.42 \pm 3.80^{c C}$ & $498.00 \pm 2.68^{\mathrm{dA}}$ & $442.21 \pm 3.46^{\mathrm{eC}}$ & 65.68 \\
\hline \multirow[t]{2}{*}{ Polypropylene } & 25 & $673.12 \pm 2.80^{\mathrm{Aa}}$ & $606.64 \pm 4.50^{\mathrm{Bb}}$ & $560.82 \pm 4.44^{\mathrm{CB}}$ & $484.12 \pm 2.68^{\mathrm{dB}}$ & $452.61 \pm 3.48^{\mathrm{eB}}$ & 67.24 \\
\hline & 40 & $673.12 \pm 2.80^{\mathrm{Aa}}$ & $600.00 \pm 3.00^{\mathrm{bB}}$ & $535.14 \pm 3.20^{c C}$ & $480.32 \pm 4.40^{\mathrm{dB}}$ & $416.91 \pm 2.89^{\mathrm{eD}}$ & 61.94 \\
\hline \multicolumn{8}{|c|}{ Values are represented as averages \pm SD. } \\
\hline \multicolumn{8}{|c|}{ Values in the same row that are followed by different superscripts (small alphabets) are significantly different $(P \leq 0.05)$. } \\
\hline \multicolumn{8}{|c|}{ Values in the same column that are followed by different superscripts (capital alphabets) are significantly different $(P \leq 0.05)$. } \\
\hline
\end{tabular}

\section{Effect of storage on the iron and vitamin A content of double micronutrient-fortified pasta}

Data for the iron and vitamin A contents of the pasta fortified with two micronutrients are shown in Table 7. With the succession in the storage time, the mean iron content of the pasta decreased significantly from 6.07 to $5.77 \mathrm{mg} / 100 \mathrm{~g}$ after 4 months of storage. Likewise, for all conditions of storage, similar trends of decline in the iron content was observed. Different storage temperatures and packaging materials had no significant impact on the stability and retention of iron of the double micronutrient-fortified pasta, with an overall retention of 94-95\%. However, stability of vitamin A in double micronutrient-fortified pasta decreased significantly $(P \leq 0.05)$ with storage period, with a maximum loss of $38.06 \%$ (propylene packets at $40{ }^{\circ} \mathrm{C}$ ) at the end of the fourth month of storage. Also, no interaction was seen among both the micronutrients on storage, with similar retention rates observed in singly fortified pasta samples. Crandall et al. (2014) also reported in their study that vitamin A stability of fortified flour was directly related to the temperature of storage and storage duration. In the same study, it was also reported that fortification of vitamin-A-fortified flour with three different iron fortificants, even when added at higher levels, had no association with the stability of vitamin A of the stored commodity when stored for 16 weeks.

\section{Proximate composition of raw semolina}

The proximate composition (moisture, ash, protein, fat, fibre and carbohydrates) of raw semolina used is discussed in the Table 1 and consisted of $1.99 \mathrm{mg} / 100 \mathrm{~g}$ iron and $22.85 \mathrm{RE} \mu \mathrm{g} / 100 \mathrm{~g}$.

\section{Conclusion}

Micronutrient fortification of pasta is a promising technology and can be employed to combat iron and vitamin A deficiencies globally. The present study revealed that after processing and storage at various conditions, the overall retention of iron observed was in the range of $89-90 \%$ and that of vitamin A was between 56 and $62 \%$, when fortified individually or in combination, considering losses at the processing and storage stages. Storage at higher temperature and exposure to light considerably reduced the stability of vitamin A in fortified pasta, necessitating special storage conditions to avoid further losses. Hence, it can be concluded that the double micronutrient-fortified pasta can help meet the recommended dietary allowances for iron and vitamin A, when consumed in sufficient quantities, and improve the nutritional status of a society.

\section{Conflict of interest}

The author(s) declared no potential conflicts of interest with respect to the research, authorship and/or publication of this article.

\section{Compliance with ethical standards}

The author(s) received no financial support for the research, authorship and/or publication of this article. 


\section{References}

AACC 2000. Approved methods of american association of cereal chemists, $10^{\text {th }}$ edition. The Association, St. Paul, MN.

Akhtar, S., Anjum, F.M., Rehman, S.U. and Sheikh, M.A., 2010. Effect of storage and baking on mineral contents of fortified whole wheat flour. Journal of Food Processing and Preservation 34: 335-349. https://doi.org/10.1111/j.1745-4549.2009.00405.x

Alam, S., Shah, U.H., Saleemulah and Riaz, A., 2007. Comparative studies on storage stability of ferrous iron in whole wheat flour and flat bread (naan). International Journal of Food Science and Nutrition 58: 54-62. https://doi.org/10.1080/09637480601121979 AOAC, 2005. Official Method of Analysis, $18^{\text {th }}$ edition. Association of Official Analytical Chemists, Gaithersburg, MD, USA.

Ayelign, A., Urga, K. and Retta, N., 2011. The stability of micronutrients in fortified food stuffs after processing and storage: iodine in salt and iron in wheat flour. African Journal of Microbiology Research 6: 4226-4232. https://doi.org/10.5897/ AJMR11.544

Bauernfeind, J.C., 1991. Foods considered for nutrient addition: fats and oils. In: Bauernfeind, J.C. and Lachance, P.A., (eds.) Nutrient additions to food. Food and Nutrition Press, CT, USA.

Butt, M.S., Arshad, M.U., Alam, M.S. and Nadeem, M.T., 2007. Bioavailability and storage stability of vitamin A fortificant (retinyl actetate) in fortified cookies. Food Research International 30: 30-36. https://doi.org/10.1016/j.foodres.2007.07.002

Chillo, S., Laverse, J., Falcone, P.M., and Nobile, M.A., 2008. Quality spaghetti in base amaranthus whole meal flour added with quinoa, broad bean and chick pea. Journal of Food Engineering 84: 101-107. https://doi.org/10.1016/j.jfoodeng.2007.04.022

Clydesdale, F.M., 1999. Mineral additives. In: Bauernfeind, J.C. and Lachance, P.A., (eds.) Nutrient addition to food: nutritional, technological and regulatory aspects. Food and Nutrition Press Inc., Trumbull, CT, USA, pp. 87-107.

Combs, G.F., Dexter, P.B., Horton, S.E. and Buescher, R., 1994. Micronutrient fortification and enrichment of P.L. 480 Title II commodities: recommendations for improvement. OMNI, Arlington, VA, USA.

Cort, W.M., Borenstein, B., Harley, J.H., Osadca, M. and Scheiner, J., 1976. Nutrient stability of fortified cereal products. Food Technology 30: 52-62.

Crandall, P.G., Seo, H.S., Pellegrino, R., O’ Bryan, C.A., Meullenet, J.F., Hettiarahachy, N.S., Washburn, A.M. and Ranhotra, G.S., 2014. Effect of storage temperature on sensory and physicochemical properties of wheat flour fortified with elevated levels of vitamin A in combination with three types of iron. Journal of Agricultural Science and Technology 4: 563-575.

Feil, B., 2001. Phytic acid. Journal of New Seeds 3: 1-35. https://doi. org/10.1300/J153v03n03_01

Food Fortification Database (FFD), 2015. Food fortification initiative. Atlanta, USA: FFI.

Flour Fortification Initiative (FFI), 2008. Second technical workshop on wheat flour fortification: practical recommendations for national application: summary report, Stone Mountain, GA, USA, March 30-April 3, 2008. Available at: http://www.sph.emory.edu/ wheatflour/atlanta08/.
Food Agriculture Organization (FAO), 2013. The state of food and agriculture 2013: food systems for better nutrition. Available at: http://www.fao.org/3/i3300e/i3300e00.htm.

Fratianni, A., Di Criscio, T., Mignogna, R. and Panfili, G., 2012. Carotenoids, tocols and retinols evolution during egg pasta-making processes. Food Chemistry 131: 590-595. https://doi.org/10.1016/ j.foodchem.2011.09.034

Herawati, D., Simanjuntak, F., Syamsir, E., Lioe, H.N. and Brianan, D., 2015. Physicochemical properties of sweet potato cookies fortified with some nutrients. International Food Research Journal 22: 684-690.

Hoffpauer, D.W. and Wright, S.L., 1994. Enrichment of rice. In: Marshall, W.E. and Wadsworth, A. (eds.), Rice science and technology. Marsh all Rekker, New York, NY, USA.

Kaur, S., Dar, B.N., Pathania, S. and Sharma, S., 2015. Reduction of anti-nutritional factors in cereal brans for product development. Journal of Food Processing and Preservation 39: 215-224. https:// doi.org/10.1111/jfpp.12223

Kongkachuichai, R., Kounhawej, A., Chavasit, V. and Charoensiri, R., 2007. Effects of various iron fortificants on sensory acceptability and shelf life stability of instant noodles. Food and Nutrition Bulletin 28: 165-172. https://doi.org/10.1177/156482650702800205

Kuong, K., Laillou, A., Chea, C., Chamman, C., Berger, J. and Wieringa, F.T., 2016. Stability of vitamin A, iron and zinc in fortified rice during storage and its impact on future national standards and programs-case study in Cambodia. Nutrients. https://doi. org/10.3390/nu8010051

Le, H.T., Brouwer, I.D., de Wolf, C.A., van der Heijden, L., Nguyen, K.C.and Kok, F.J., 2007. Suitability of instant noodles for iron fortification to combat iron-deficiency anemia among primary schoolchildren in rural Vietnam. Food and Nutrition Bulletin 3: 291-298. https://doi.org/10.1177/156482650702800305

Lee, J., Hammer. M.L. and Eitenmiller, R.R., 2000. Stability of retinyl palmitate during cooking and storage in rice fortified with ultra rice ${ }^{\mathrm{TM}}$ fortification technology. Journal of Food Science 65: 915-919. https://doi.org/10.1111/j.1365-2621.2000.tb13612.x

Li, Y., Diosady, L.L. and Jankowski, S., 2008. Effect of iron compounds on the storage stability of multiple-fortified ultra rice. International Journal of Food Science Technology 43: 423-429. https://doi.org/10.1111/j.1365-2621.2006.01457.x

Miller, D.M., 2008. Minerals. In: Damodaran, S., Parkin, K.L. and Fenemma, O.W. (eds.) Fenemma's food chemistry, $4^{\text {th }}$ edition. CRC Press, Boca Raton, FL, USA, pp. 439-521.

Ministry of Health of the People's Republic of China, 2010. National standard for food safety of the People's Republic of China, National food safety standard, Determination of vitamin A, D and E in food infant and young children and milk products. Available at: http:// china.nlambasssade.org/binaries/content/assets/postenweb/ china/zaken-dleon-in-china/2013/productstandardaarden-zuivel/ gb5413.9-2010-determination-of-vitamin-a-d-e-in-foods-for-infants-and-young-children-milk-and-milk-products.pdf.

Molina, M.R., 1991. Foods considered for nutrient addition: sugars. In: Bauernfeind J.C. and Lachance P.A. (eds.). Food and Nutrition Press, CT, USA.

Nestel, P., 1993. Food fortification in developing countries. U.S. Agency for International Development. 
Ott, D.B., 1988. The effect of packaging on vitamin stability in cereal grain products-A review. Journal of Food Composition and Analysis 1: 189-201. https://doi.org/10.1016/0889-1575(88)90023-3

Pinkaew, S., Wegmuller, R. and Hurrell, R., 2012. Vitamin A stability in triple fortified extruded, artificial grains containing iron, zinc and vitamin A. International Journal Food Science Technology. https://doi.org/10.1111/j.1365-2621.2012.03091.x

Ranganna, S., 1986. Handbook of analysis and quality control for fruit and vegetable products. 2nd edition. New Delhi: McGraw-Hill.

Ranum, P., 2000. Fortification of high extraction wheat flour. Cereal Foods World 45: 267-268. DOI: 10.1177/15648265100311S102

Reungmaneepaitoon, S. and Sikkhamondhol, C., 2008. Development of pasta products from high-iron rice and iron-fortified rice flour. Natural Sciences 42: 367-375.

Richins, A.T., Burton, K.E., Pahulu, H.F., Jefferies, L. and Dunn, M.L., 2008. Effect of iron source on color and appearance of micronutrient-fortified corn flour tortillas. Cereal Chemistry 85: 561-565. https://doi.org/10.1094/CCHEM-85-4-0561

Rosado, L.J., Cassis, L., Solano, L. and Duarte-Vazquez, M.A., 2005. Nutrient addition to corn masa flour: effect on corn flour stability, nutrient loss, and acceptability of fortified corn tortillas. Food and Nutrition Bulletin 26: 266-272. https://doi.org/10.1177/ 156482650502600303

Runge, F.E. and Heger, R., 2000. Use of microcalorimetry in monitoring stability studies. Example: vitamin A esters. Journal of Agricultural and Food Chemistry 48: 47-55. https://doi. org/10.1021/jf981163y

Theuer, R., 2002. Effect of iron on the color of barley and other cereal porridges. Journal of Food Science 67: 1208-1211. https://doi. org/10.1111/j.1365-2621.2002.tb09478.x

Tripathi, B., Platel, K. and Srinivasan, K., 2012. Double fortification of sorghum (Sorghum bicolor L. Moench) and finger millet (Eleusine coracana L. Gaertn) flours with iron and zinc. Journal of Cereal Science 55: 195-201. https://doi.org/10.1016/j.jcs. 2011.11.008

World Health Organization and Food and Agricultural Organization., 2006. Guidelines of fortification of food with micronutrient. In: Allen, L., De Benoist, B., Dary, O., Hurrell, R. (eds.). World health Organization.

WHO, 2009. Global prevalence of vitamin A deficiency in populations at risk 1995-2005. WHO Global Database on vitamin A deficiency, World Health Organization, Geneva, Switzerland. 